\title{
Improving the livelihoods of the poor and marginalized in Nepal through leasehold forestry and livestock program: A review of institutional constraints and opportunities
}

\author{
B.R. Regmi ${ }^{1}$, A. Albano ${ }^{2}$, C. Kumar ${ }^{2}$, G.B. Sharma ${ }^{1}$
}

\begin{abstract}
The study looks at the opportunities and constraints of the contributions made by forest institutions to improve the livelihoods of the poorest, through an analysis of the Leasehold Forestry (LF) programme in Nepal - a forestry programme that aims to help alleviate poverty of forest dependent communities by leasing degraded land to the poorest. Data and analysis were primarily based from review of literature, consultations with key informants, field visits, and complemented by the authors' direct involvement in the implementation of LF programme. Although intended to improve the lives of the poorest, the LF programme could negatively affect the poorest when it excludes them or when it causes their displacement from the land that the poorest depend for their livelihoods. Such negative impacts of LF program can be attributed to its improper implementation and design. To improve its effectiveness and impact, awareness campaigns should be improved using diverse modes of communication, more line agencies should be involved in the implementation by transferring the implementation responsibility to a district-level project coordination committee, and some programme provisions should be changed in favour of the poor.
\end{abstract}

Key words: Forest institutions, leasehold forestry, poverty alleviation, Nepal

A $\mathrm{n}$ increasingly popular school of thought on improving the livelihoods of the poor is to increase their access to the resources or "assets" they needed to make a living, by reforming institutions governing access, more favorable for the poor. This school of thought has been apparent in the trend of national forest policies of developing countries towards community-based forest management, which in principle, gives forest communities greater access rights to forest resources. However, despite changes in forest policies, it is a fact that many forest communities still have difficulty accessing forest resources. Notwithstanding the complexity of improving the livelihoods of poor forest communities, such difficulty underscores the constraints in implementing new, and presumably, more favorable institutions.

In Nepal, the shift in national forestry policy towards greater access for forest users has resulted in the institutionalization of various Community based Forest Management (CBFM) programmes. One of these programmes is the Leasehold Forestry Programme (LFP) which aims to improve the livelihoods of the poorest, by offering them access rights over degraded forest land. Although various studies have demonstrated the positive impacts of the LFP, other studies have also pointed out many of its limitations. One such limitation is in its ineffective implementation (Thoms et al. 2006).

This paper looks at the implementation aspect of institutional reform for the case of the LFP in Nepal. This study aims to develop a better understanding of the processes in the formation and make up of forestry institutions as well as the constraints on their effective implementation. In doing so, this study describes the existing forest institutions in Nepal, focusing on the LFP, in particular; identifies institutional constraints for its effective implementation; and recommends measures to improve the LFP or other similar forestry programmes in favor of the poorest. This study was conducted primarily through a review of related literature; consultations with key informants involved in the LFP; field visits to leasehold and community forest user groups; and from the authors' experiences working with Leasehold Forestry User Groups (LFUGs).

\footnotetext{
${ }^{1}$ LI-BIRD, POBOX 324, Pokhara, Kaski, Nepal

${ }^{2}$ Centre for International Forestry Research (CIFOR), Bogor, Indonesia
} 


\section{Materials and methods}

The study was carried out through a desk study of a number of published and unpublished literature on community forestry, leasehold forestry and other related subjects in Nepal; supplemented with consultation of the stakeholders; and the Collaboration/Conflict, Legitimacy, Interest and Power (CLIP) analysis.

The review of forestry and livelihoods related key literatures focused on the critical analysis of the current situation and how different programs and approaches were addressing it. Besides, various journal articles were also reviewed. Workshop proceedings were important sources of information for analyzing recent research and development highlights in the forestry sector of Nepal, and over viewing what is happening in forestry sector now? who is doing what? and what are the good practices and lessons learnt? Program and project related papers, the review reports and technical papers were also relevant to the analysis. The documents of various projects and programmes were useful in analyzing the approaches and strategies for inclusion, governance and sustainable resource management in community forestry.

Consultations were made with government staffs, I/ NGOs personnel and the CFUGs working in community forestry and leasehold forestry in Nepal. This was done through series of meetings with relevant stakeholders including government line agencies. A number of consultation meetings were organized both at individual and organizational levels during the preliminary stage of the study. The main objective of this consultation was to collect relevant literature, inform them about the study as well as to gauge their perceptions about the research problem. Furthermore, a brief questionnaire was used to capture the perceptions of different stakeholders in understanding the current socio-structural context and their suggestions for improvement.

One-day stakeholder meeting was organized whe major stakeholders of CF and LF were invited. The workshop venue was used to carry out CLIP analysis ${ }^{3}$. CLIP tool was used in this study in order to ascertain various opportunities and constraints as perceived by 'key stakeholders' in the forestry sector. The CLIP workshop included representation from CFUGs, LFUGs, researchers as well as partners and other stakeholders from government agencies.

\section{Result and discussion}

\section{The leasehold forestry programme}

The LFP is one of the community-based forest management (CBFM) programmes being implemented by the Government of Nepal. It was first initiated in 1993 through the implementation of the first leasehold forestry project called the Hills Leasehold Forestry and Forage Development Project (HLFFDP). This was introduced primarily due to the widespread discrimination of the poorest, observed within the CFUGs, formed in the earlier CF programme and the necessity to mainstream the poor and marginalized groups into the overall national development.

Basically, $\mathrm{LF}$ is similar to CBFM programmes wherein forest users are organized into Forest User Groups (FUGs) and are awarded with rights and responsibilities to manage a patch of forest. The LFUGs have the same organizational structure and institution-making process as CFUGs. They prepare an Operational Plan (OP) with substantial assistance from the forest rangers. The LFP, however, tries to target the poorest members of the forest community and hands over degraded 'forests' through a 40-year leasehold agreement. As the LFP specifically targets the poorest of the poor ${ }^{4}$, the groups are smaller in size, with around 5 to 15 members in one Leasehold Forest User Group (LFUG). Due to the livestock promotion component, LFP involves the Department of Livestock (DoLS) and other local service providers besides Department of Forest (DoF) in its implementation.

\section{Impacts}

The programme demonstrated success in achieving its objective of improving the livelihoods of its targeted poorest. Studies show that it (i) increased the assets of the poor, especially their livestock holdings (ii) improved the productivity of women and their participation in group activities and decision-making; and (iii) increased school attendance

\footnotetext{
${ }^{3}$ Collaboration/Conflict, Legitimacy, Interest and Power (CLIP) is a social analysis tool used in understanding the dynamics of stakeholders, their interest, power and legitimacy

${ }^{4}$ The poorest are to be identified based on the National Planning Commission (NPC)'s poverty threshold criteria which are based on type of dwelling, land/asset holding and food security.
} 
and improved nutrition of the member-households especially of their children (Ohler 2003; HLFFDP 2003). The evidences of positive impacts provided a strong rationale for International Fund for Agriculture Development (IFAD) and the Government of Nepal to continue to support the approach of the programme, creating the Leasehold Forestry and Livestock Programme (LFLP) which would continue to implement the strategies of the HLFFDP and extending it further to 26 more districts.

Despite its achievements, several studies have also revealed constraints in the programme. Although the programme intends to target the poorest communities, many studies have demonstrated that in reality many of such households were left out and as a result, were further impoverished (Grinten and Dhakal 1997; Schuler 1997; Joshi et al 2000; Dhakal and Yadav 2000; Bhattarai et al 2003; Baral and Thapa 2003). The programme also resulted in conflict between LFUG and non-LFUGs, usually due to conflict over rights to the land being handed over and conflict over who are supposed to be included within the LFUGs (see for example Bhattarai, et al 2003; LI-BIRD 2004). ${ }^{5}$

Considering its further extension and expansion into a national programme, the obvious direction for improvement is to further increase its positive impacts while minimizing or eliminating its negative impacts. These require an analysis of the causes of its negative consequences and constraints.

\section{Issues and constraints}

There are various issues and constraints about the LFP that are cited in the literature. Given our focus on institutional constraints, we may limit the issues about the constraints on its implementation, and less on its provisions or design. We may present these issues at different levels of implementation i.e. at the community, programme and implementation, and policy level.

\section{Constraints at community level}

A primary issue at the community level is about equity, particularly the exclusion of the poorest in the programmes and eventually from the benefits generated from it; in some cases, the displacement of the poorest, in case of communities involved in shifting cultivation, as a consequence of this programme. Various reasons were offered to explain the exclusion of the poorest. One of these is the lack of awareness of the LF programme. The evaluation report of LFLP shows that not all the poor households received prior information about the selection of LFUG members. In many cases, these were reinforced by the remote geographical location of the poorest and poor infrastructure which limits the flow of information and mobility of the people (LFLP, 2005). As a result, there are evidences where some middle class and even richer households are included in the LFUGs (see Baral and Thapa 2003 and Bhattarai, 2003). These studies support the earlier study by Grinten and Dhakal (1997) which revealed that many leaseholder households are large landholding farming families. In addition, some of the Leasehold Forest (LF) members have dropped out as they could not fulfill some requirements of LF membership such as regular attendance in meetings and other leasehold forestry activities which are required to maintain membership (LI-BIRD, 2004).

\section{Implementation constraints}

Obviously, the exclusion of the poorest is the opposite of what the programme intended to do and do not follow the design of the leasehold forestry implementation process. Many of the negative impacts of the programme can thus be attributed to its weaknesses in its implementation, particularly, the lack of capacity of its main implementing agency and weakness in monitoring implementation to conform to the appropriate process of implementation as designed.

\section{Lack of capacity of DFOs}

Although a multi-partner programme, the LF is still primarily being implemented by the DoF through its District Forest Office (DFOs), who are also implementing other CBFM programmes. Definitely for the DFOs and their forest rangers, the implementation of another programme would mean additional work. With no additional multidisciplinary staff besides forestry added to implement the LFP, the DFO and their staff would have to juggle their time and resources to accommodate the LFP, often resulting in shortcuts in the processes; and consequently, to lesser quality output. In addition, rangers often manage to provide training to groups

\footnotetext{
${ }^{5}$ The Programme is also criticized for low impact (i.e. very few people benefited) considering the investment made of around US\$17 million implemented within seven years (see Yadav and Dhakal 2000).
} 
even without much experience and expertise in the subject matter. Partly the problem lies in the limitation of both human and financial resources.

\section{Lack of monitoring and weaknesses in evaluation}

In principle, the LFP process of handing over forests to the poorest tries to minimize exclusion of the poorest as it is for this reason that this programme was introduced in the first place. However, as was demonstrated above, in many cases, forest handovers and the selection of recipients were not done as was designed or intended. Much of these constraints can be attributed to how programme implementation is monitored and outputs evaluated. Although participatory monitoring and evaluation was mentioned as one of the features of the programme, in reality, this is hardly done. Outputs are measured at the end of the project mostly based on quantity (e.g. number of households organized; area of degraded forests covered; number of training provided) rather than on quality (i.e. number of households getting off the poverty line; sustainability of livelihood projects implemented, and of LFUG groups). Communities often complain that the visit of rangers will be negligible immediately after the first year of implementation (LI-BIRD, 2004). Because of the emphasis on quantity outputs, line agencies often do not follow the ideal processes of implementation. Instead, they do some 'shortcut' methods such as not consulting the whole community in the identification of degraded land or in identifying the poorest, which could then later result to conflicts and unfair community forest institution through the $\mathrm{LFP}^{6}$.

\section{Design constraints}

The constraints in the effective implementation of the programme can also be further attributed to its design.

\section{Lack of capacity of User groups}

Many of the constraints earlier mentioned can be attributed to the fact that the people being targeted and organized are the poorest. Being poor, they cannot afford to invest their time and resources to activities other than those that will give them immediate returns. They also lack the power to prevent other people from claiming their rights like the ones being provided through the LF programme. They are often illiterate, living remotely, or indebted to the better off households in their neighborhood ${ }^{7}$. These groups (particularly the genuinely poorest) need more than just two years of institutional and technical support but apparently, the project implementation is designed for such a short period of capacity building.

The lack of capacity of the LFUGs can also be attributed to their very small membership composition. The current leasehold groups range from 5-15 households, which are very small compared to CFUGs or other farmers group. This is a disadvantage when accessing external support since NGOs and other civil society organization look for a sizable community groups for collaboration and work. For example, there would be a problem registering LFUGs with the District Agriculture Development Office (DADO) and other district line agencies which require larger membership for them to provide support services.

\section{Limited livelihood options under LF}

Under the LFP, the cultivation of cereal crops is prohibited; only grasses, fodder, and trees are allowed. For a poor farmer who cultivates vegetables or cereal crops on a 'degraded' land, converting the land as a leasehold forest would mean that he/she will no longer be allowed to cultivate them. Growing grasses or trees would not be rational because it would take months or even years before they are harvested. On the other hand, once the land being cultivated by these poor farmers are identified as degraded land, they would have not much choice but to yield since they do not have ownership rights over these lands because according to law, these are government-owned land ${ }^{8}$.

\section{Opportunities for interventions: a stakeholder analysis}

In identifying opportunities for interventions, it is important to have a better understanding of the LF institutions - the various interests in shaping them and their power to influence reform. In this regard,

\footnotetext{
${ }^{6}$ For more discussion and empirical studies on this subject see Thoms et al. 2003; Bhattarai et al. 2003

${ }^{7}$ If the degraded forests is open to any interested lessee/s (not excluding the better off households), implementation would have been faster (although it may no longer be a pro-poor endeavor).

${ }^{8} \mathrm{An}$ example for this case is the Chepang communities that were reluctant to join the programme due to this policy which prohibits them from growing of agricultural crops in the sloping land. Since these communities do not have any other alternative land for growing the crops, they feel insecure about joining the LF programme (LI-BIRD, 2004).
} 
analysis of the stakeholders in LF was conducted through an analytical tool called CLIP9 analysis. This tool enables a better understanding of the relationship among the various stakeholders particularly, those who are bound to be in conflict or to collaborate.

Based on the general commonality in their interest and mandate on forestry, an initial list of LF stakeholders include the government through the Ministry of Forests and Soil Conservation (MoFSC), with its various departments such as the DoF - the primary government agency that oversees forest in Nepal, forest users including LFUG and non-LFUG members, donors including IFAD, and the social mobilizers including local Non-Governmental Organizations (NGOs). Most of these groupings could still, however, be further categorized into subgroups based on their differences in interest on the forest resources being handed over or over other benefits from the programme, their legitimacy to influence leasehold forestry institutions based on existing law, and their overall power to effect reform on leasehold forestry institutions.

Within the government, the interests, legitimacy and power of the central office is often different from the implementing line agencies. At the central office, the LF is managed by a separate office: the LFLP office. The LFLP office is obligated to coordinate the implementation of the programme under the DoF. It has the power mostly on the implementation of the programme as well as partly on the policy or design of the programme. Within this group is also included the National Planning Commission (NPC) that is responsible for preparing the national poverty reduction strategy paper for Nepal, which is then used as a basis in the design of poverty reduction programmes such as the LF. At the implementation level, the programme is mainly being implemented by the DFO and District Livestock Office. Altogether, these three government offices (i.e. LFLP central office, DFO, DLSO) have the mandate to implement the programme and therefore have the legitimacy. They benefit from the implementation of the programme and therefore have high interest in LF. And they have the power to reform or not to reform the existing LF institutions. Aside from them, there are also other government agencies that may have interest or legitimacy to get involved in the LF programme but currently lack the power to get involved and influence the implementation. These include the DADO which has the mandate to implement agricultural related activities and the District Development Committee (DDC) which is the local government body at the district level authorized to manage district resources (including forest resources) through the Local Self-Governance Act of 1998 .

The forest users could also be further categorized into different stakeholders. Foremost of these would be the LFUG members as they are the recipients of the programme. Another sub-group would be those who were left out particularly the shifting cultivators who often have claims over the degraded lands but have high probability of not being included, and the rest of the community members who would not be members of the LFUGs, or non-LFUG members.

The list of LF stakeholders could then include the LFLP office, DFO, DLSO, DADO, DDC, NPC, LFUGs, shifting cultivators, non-LFUG members, IFAD, and the various local NGO contracted as social mobilizers. These stakeholders and their relationship based on the analysis of their legitimacy, interest, and power can be illustrated in Figure 1 below.

Fig. 1: LF Stakeholder analysis

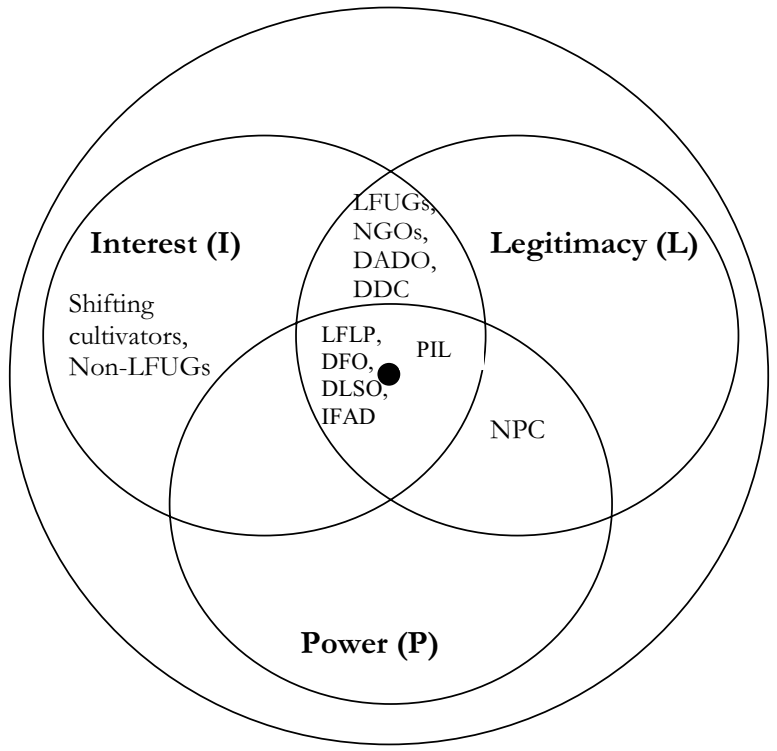

From the above analysis, and as partially illustrated in Figure 1, some important observations about the relationship of the stakeholders are: a) forest communities in general have high interest in LF but lack the legitimacy and power to influence LF institutions to their favor; b) although LFUGs have

\footnotetext{
${ }^{9}$ Refer to http://www.sas-pm.com/ for details about the tool
} 
high interest and legitimacy to influence LF policies, they lack power to do so. This is true for other line agencies such as the DDC and DADO, and even the NGOs involved in social mobilization process; and c) among the government line agencies, the highest stake, legitimacy and power over LF institutions is mostly concentrated with the DoF through the LFLP at the central office and the DFOs at the districts. The NPC also has the legitimacy and power to influence the design of the programme, but its interest in intervening with LF institutions is limited. Other stakeholders that have high interest, legitimacy, and power to change LF institutions are IFAD and DLSO. This shows that most of the interventions towards institutional reforms can mostly be done by the government policy-makers and implementers.

\section{Discussion and direction for interventions}

Given the various institutional constraints at different levels and the analysis of the roles of the various stakeholders, various areas can be identified for interventions to improve the implementation and impact of the LFP.

\section{Community level}

The dominant issue under at the community-level is exclusion of the poorest with the forest rangers not following the process of selection of the poorest and degraded land. Intervention should be done to find out whether the process is strictly followed at the community level or not.

One way to do this is to improve the awareness of the communities towards LFP. To do this, innovative means of information dissemination need to be considered. This may include placing posters (about the process of handover) in places frequented by the poorest, and use of local radio to reach out those at remote locations. It was also mentioned that LFUGs do not have constitution that states these rights and responsibilities. In a way, this is due to the reality of preparing a constitution (which for LFUGs would need heavy external assistance just like the preparation of their OPs). On the other hand, LFUGs are being organized into inter-groups and cooperatives which necessitate their preparation of their constitution and by-laws. Intervention should target improving the awareness of LFUG members of their rights and responsibilities, including support for the formation of inter-groups and common-interest associations.
Community awareness campaign may also target not just the recipients but also the wealthier and the privileged groups in the community, with the aim of changing their attitude to be more favorable for the poorest.

\section{Programme implementation level}

Both DFOs and DLSOs - the primary implementing agencies of the programme - are limited in their capacity partly by their number of staff but especially their sectoral mandate, resulting in their limited collaboration with other line agencies. Programme implementation then needs to involve other government line agencies in the implementation of the programme such as the DADO, District Soil Conservation Office, and the DDC.

A district-level project coordination committee should be formed to manage or supervise the implementation of the LFP. This committee shall be under the chairmanship of the DDC chairperson. Following the Local Self-Governance Act of 1998 which provides the DDC greater jurisdiction over forest resources, the DDCs have the mandate to implement government programmes at the district level and to coordinate various sectoral activities from various government departments. The DFO could be the secretary of the DDC while other district line agencies including representatives from NGOs and user groups shall be members. This reorganization in the implementation of the programme is needed because the poorest have diverse needs (such as food and nutrition, education, health, income, etc.) and they need integrated and varying interventions to address these needs

This recommended reorganization in the implementation of the LF programme surely would need clarification on the roles of the line agencies involved, or that shall be involved. A very important issue that would need to be resolved (as this would be the main source of controversy) would be the distribution of programme and project funds (i.e. what are the incentives for getting involved in the programme?). Definitely, the DFO will oppose reducing their share of the budget while all other will want their share. Since this is a controversial issue, further discussion involving the various stakeholders is recommended. On the other hand, we suppose that this re-organization would take some processes and time to be resolved. Furthermore there exists a number of complications in coordination not just 
among the line agencies but between them and other stakeholders such as the donor agency (IFAD), national coordinating body (i.e. LFLP), and LFUGs. A way forward is to conduct a pilot project that would implement the programme with the proposed organizational structure to see how this recommendation can actually be realized.

\section{Programme design level}

Although many of the constraints discussed can be attributed to the design of the programme (e.g. limitations in land quality, cultivable crops, land area, membership composition), it is a fact that changing such design or provisions have their own rationale or purpose (e.g. to improve forest cover). Changing legal provisions is not easy either because of the lengthy process of policy-making or because such provisions are often controversial. Changing the provisions of the LFP has to start by facilitating a dialogue among the concerned stakeholders to discuss and compromise that ideally will satisfy the interests of the stakeholders, and particularly the poor. The smaller leasehold groups of the same locality or VDC (5-15 members) including other existing groups of discipline should be federated to a coordination committee so that it can minimize duplication and facilitate wise use of resources. These dialogues may be initiated by those representing the interest of the poorest such as the civil society organizations including the organization of forest users (eg. FECOFUN, NEFUG); or could better be initiated by IFAD using its power to influence actions of the respective government agencies.

\section{Conclusion}

Institutional reform not only require changes in the rules or policy provisions but especially support to make sure that such changes are implemented properly. Implementation of changes by the concerned forestry institutions has, however, become complex by the presence of various conflicting interests over forest resources. These interests are needed to be understood in order to understand how such institutions are shaped and how they can be made more favorable for the interest of the poor. Furthermore, implementation of changes is made difficult by the lack of capacity of implementing agencies; for forest institutions and poverty alleviation programs, by the sectoral nature of government implementing agencies. Institutional reform needs to be complemented by capacity building support. In the case of forestry programs with integrated approaches to livelihoods improvement, capacity building may mean implementing the programme alongside other sectoral agencies.

\section{Acknowledgements}

The authors are grateful to the Centre for International Forestry Research (CIFOR) and IFAD for the opportunity awarded to carry out this study. The authors would like to highly acknowledge the guidance, supervision and technical input provided by Govinda Kafley, and Brian Belcher during the study. We would also like to appreciate the support provided by Dr. Pratap Kumar Shrestha, Diwakar Poudel, Nirmal Duwadi, Santanu Regmi, Dhurba Acharya, Govinda Sharma, Gyan Bandu Sharma, Erica Udas, Laxman Gautam, Arjun Dhakal, Arjun Basnet, Dr. Bhuwon R. Sthapit, Anu Adhikari and Bir Bahadur Tamang. Finally, the authors would like to extend their sincere thanks to all the stakeholders and professional experts for sharing their views and input.

\section{References}

Baral, J. C. and Thapa, Y. 2003. Nepal's Leasehold Forestry for the Poor: The other Side of the Coin', In Timsina, N. P. and H. Ojha Eds. (2004). Case Studies on Equity and Poverty in the Management of Common Property Resources in Nepal. Proceedings of the National Workshop on Management of Common Property Resources and Equity: Exploring Lessons from Nepal, May 28, 2003.

Bardhan, P. 2005. Institutions matter, but which ones?' Economics of Transition, 13 (3): 499-532.

Bebbington, A. 2000. Reencountering development: livelihood transitions and place transformations in the Andes,' Annals of the Association of American Geographers, 90(3): 495-520.

Bhattarai, B., Ojha, H. and Humagain, Y. 2004. Is Leasehold Forestry Really a Pro-Poor Innovation? Evidences from Kavre District, Nepal', Journal of Forest and Livelihoods. Vol 4 (2), February 2005.

Bhattarai, B., Ojha, H. and Humagain, Y. 2003. Equity through exclusion? Leasehold forest and livelihood of the poor, a case study of Charpipal LFUG, Bhagavatisthan, Kabre, Kathmandu', ForestAction (unpublished draft).

Grinten, P. v.d. and Dhakal, H. H.1997. Household Impact Study II Volume: Main Report', Hills 
Leasehold Forestry and Forage Development Project, Kathmandu, Nepal.

HLFFDP. 2003. Hills Leasehold Forestry and Forage Development Project: Interim Evaluation, Volume 1 Main Report. IFAD- Office of Evaluation, Italy.

LFLP. 2005. Leasehold Forestry and Livestock Programme Design Document-Appraisal, Main Report.

LI-BIRD. 2004. Documentation innovations in Shifting Cultivation Areas of Nepal. Nepal Case studies.

Ohler, F.M.J. 2003. The impact of leasebold forestry on livelihoods in Nepal, Paper presented to the XIIth World Congress of Forestry, Quebec, Canada, September 21-28, 2003.

Schuler, K. 1997. Intent of Integration of Community Forestry and Leasehold Forestry in Ramechbap,' Seminar on Leasehold Forestry and Forage Development for the poor. August 24-28, Hills Leasehold Forestry and Forage Development Project, Kathmandu.

Scoones, I. 1998. Sustainable rural livelihoods: a framework for analysis,' Institute of Development Studies (IDS), Brighton.

Thoms, C. 2004. Livelihoods forestry in Rural Nepal: the need for partnership,' A Paper Presented at the 2004 Rural Sociological Society's 67th Annual Meeting in Sacramento, California.

Yadav, R.P., and Dhakal, A. 2000. Leasehold Forestry for Poor: An Innovative Pro-Poor Programme in the Hills of Nepal, Policy Outlook Series No. 6, Kathmandu: HMGN Ministry of Agriculture/ Winrock International, Programme on Policy Analysis in Agriculture and Related Resource Management. 